\title{
A Prospective Comparative Study of Chemical Sphincterotomy (Using 2\%Diltiazem) And Lateral Internal Sphincterotomy For Chronic Fissure in Ano
}

\author{
*Rajasekar $\mathrm{M}^{1}$,Dhanapal P. V. ${ }^{2}$ \\ ${ }^{1}$ Associate Professor, Department Of General Surgery, Government Mohan Kumaramangalam Medical \\ College, Salem. \\ ${ }^{2}$ Associate Professor, Department Of General Surgery, Government Mohan Kumaramangalam Medical \\ College, Salem.
}

\begin{abstract}
Anal fissure is the most common problem in our day to day practice. This study is a prospective comparative study of chemical sphincterotomy and lateral internal sphincterotomy for the treatment of chronic fissure in ano. Chronic fissure in ano is the failure of fissure to heal for more than 6 months. The aims of this study is to compare the efficacy of these two techniques and their complications. This study helps to decide the better treatment for chronic fissure. Data obtained from 100 patients attending General Surgical Out Patient Department of all units in Govt Mohan Kumaramangalam Medical College Hospital, Salem presenting with chronic anal fissure were subjected to statistical analysis. The subjects were thoroughly examined and subjected randomly by dividing them into two groups of 50 each. One group was subjected to Lateral Internal (Surgical) Sphincterotomy. The other group was subjected to Chemical Sphincterotomy. The outcome of each procedure were assessed during follow up. This study at the end shows results in favor of lateral internal sphincterotomy with healing rate of $100 \%$ with faster pain relief and minimal complication. Topical $2 \%$ diltiazem gel is an effective agent though there is latency in the clearance of symptoms compared to surgical sphincterotomy. The healing rate of the fissure is much slower compared to surgery. This study concludes that Lateral Internal Sphincterotomy appears to be the better line of treatment as there is $100 \%$ healing rate.
\end{abstract}

\section{Introduction}

Painful conditions of anal and perianal region are a group of conditions that had been affecting the mankind since time immemorial. These are not only frequently encountered problems in surgical practice but had also caused significant discomfort to the patients and hence deserves treatment that is curative as well as less invasive. Developments in the pharmacological understanding of the internal anal sphincter have resulted in more conservative approaches towards treatment. Anal fissure, a common disease that is encountered in the day to day practice of a Surgeon, was first described by Recamier in1829. It is a tear in the anoderm that is the squamous lining of anal canal between pectinate line and anal verge which is associated with symptoms like painful defecation, anal sphincter spasm and bleeding per rectum, which occurs linear streaks of blood that spurts on the pan before defecation ${ }^{1}$. Pain while defecation is excessive that may be associated sometimes, with sphincter spasm, when it is severe. This leads to hardening of the stools, which further tear the anoderm during defecation, setting a vicious cycle. Fissure in ano is seen in all ages and both sexes. The fissures can be classified into 1] Acute or superficial and 2] Chronic fissure in ano. Those lesions that fail to heal even after six months are referred as chronic anal fissure ${ }^{2}$. Chronic fissure in ano is usually deeper and has exposed internal sphincter fibres and is frequently associated with hypertrophied anal papilla at is upper aspect and sentinel pile at its distal aspect. Painful fissure are generally associated with spasm of internal sphincter .The internal sphincters along with the external sphincter are responsible for maintenance of continence .The tear in anoderm exposing Internal sphincters causes severe pain.Chronic anal fissure are caused due to raised anal canal pressure secondary to hyper tonicity of internal sphincter and hence treatment is targeted at eliminating this surgical technique like lateral internal sphincterotomy effectively heal most fissure within weeks but may result in anal incontinence which may be permanent. To avoid these problems alternate non-surgical treatment was tried and thus 'Chemical Sphincterotomy' is being investigated. Topical Nitroglycerine ointment was shown effective in treating chronic fissure but has reduced compliance due to head as side effects ${ }^{3}$. Topical calcium channel blockers offer a suitable alternative for fissure treating, healing $60-95 \%$ cases with lesser side effects ${ }^{4}$. Topical $2 \%$ diltiazem gel has been reported to cause healing of chronic anal fissure with reduced adverse side effect in previous studies. ${ }^{5}$. The present study comprises the comparison of $2 \%$ Diltiazem gel application and lateral internal in treatment of chronic fissure in ano with respect to both efficacy and complication. 


\section{Aims And Objectives}

To assess and compare the efficacy and adverse effects of topical application of $2 \%$ Diltiazem gel with that of Lateral internal sphincterotomy in patients diagnosed with chronic anal fissure. To compare the complications associated with both the modalities of treatment. To decide on the better treatment for chronic anal fissure based on the findings of the study.

\section{Materials And Methods}

This study was conducted in Government Mohan Kumaramangalam Medical College Hospital, Salem from December 2012 to August 2014.CASE SELECTION: The study population consists of patients presenting in the General Surgical out patient department with complaints of bleeding PR/ constipation/painful defecation for more than 6 months and diagnosed as a case of chronic fissure in ano at Government Mohan Kumaramangalam Medical College Hospital, Salem. INCLUSION CRITERIA:All patients who presented to the surgical out patient department with complaints of bleeding per rectum or constipation or painful defecation for more than six months diagnosed as chronic fissure were included in the study. EXCLUSION CRITERIA: All patients who presented with these symptoms for less than six months were excluded from our study.

\section{Observation And Results}

Data obtained from 100 patients attending General Surgical Out Patient Department of all units in Govt Mohan Kumaramangalam Medical College Hospital, Salem presenting with chronic anal fissure were subjected to statistical analysis. The subjects were thoroughly examined and subjected randomly by dividing them into two groups of 50 each. One group was subjected to Lateral Internal (Surgical) Sphincterotomy. The other group was subjected to Chemical Sphincterotomy.The outcome of each procedure were assessed during follow up.This was summarised into a master chart. The collected data was analysed with SPSS 16.0 version. The comparable tabulations permit certain statistical inferences to be made which are displayed below.

Table 01: Distribution Of Cases In Different Age Group

\begin{tabular}{|c|c|c|}
\hline Age in years & Number of cases & Percentage \\
\hline $11-20$ & 05 & 5.0 \\
\hline $21-30$ & 18 & 18.0 \\
\hline $31-40$ & 26 & 26.0 \\
\hline $41-50$ & 33 & 33.0 \\
\hline $51-60$ & 17 & 17.0 \\
\hline$>60$ & 01 & 1.0 \\
\hline Total & $\mathbf{1 0 0}$ & $\mathbf{1 0 0 . 0}$ \\
\hline
\end{tabular}

From the above table it is observed that, $35.8 \%$ of the male patient are in the age group $41-50$ years and $36.4 \%$ of female are in the age group of $31-40$ years

Table 2 : Age With Sexwise Distribution

\begin{tabular}{|c|c|c|c|c|c|c|}
\hline & \multicolumn{2}{|c|}{ Male } & \multicolumn{2}{c|}{ Female } & \multicolumn{2}{c|}{ Total } \\
\hline & No & $\%$ & No & $\%$ & No & $\%$ \\
\hline $\mathbf{1 1 - 2 0}$ & 2 & 3 & 3 & 9.1 & 5 & 5 \\
\hline $\mathbf{2 1 - 3 0}$ & 12 & 17.9 & 6 & 18.2 & 18 & 18 \\
\hline $\mathbf{3 1 - 4 0}$ & 14 & 20.9 & 12 & 36.4 & 26 & 26 \\
\hline $\mathbf{4 1 - 5 0}$ & 24 & 35.8 & 9 & 27.3 & 33 & 33 \\
\hline $\mathbf{5 1 - 6 0}$ & 14 & 20.9 & 3 & 9.1 & 17 & 17 \\
\hline$>\mathbf{6 0}$ & 1 & 1.5 & 0 & 0 & 1 & 1 \\
\hline & 67 & 100 & 33 & 100 & 100 & 100 \\
\hline
\end{tabular}

Table -3 Sex Distribution

\begin{tabular}{|l|l|l|}
\hline Sex & No Of Cases & Percentage \\
\hline Males & 33 & 33.0 \\
\hline Females & 67 & 67.0 \\
\hline Total & $\mathbf{1 0 0}$ & $\mathbf{1 0 0 . 0}$ \\
\hline
\end{tabular}

In our study of 100 patients, there were $67 \%$ of male patients and $33 \%$ of female patients with male female ratioof 2:1. 
Table $\mathbf{- 4}$ sex wise distribution of symptoms :

\begin{tabular}{|c|c|c|c|c|c|c|}
\hline \multirow{2}{*}{ Symptoms } & \multicolumn{2}{|c|}{ Male } & \multicolumn{2}{c|}{ Female } & \multicolumn{2}{c|}{ Total } \\
\cline { 2 - 7 } & No & $\%$ & No & $\%$ & No & $\%$ \\
\hline \multirow{2}{*}{ PD } & 67 & 100 & 33 & 100 & 100 & 100 \\
\hline BPR & 66 & 98.5 & 33 & 100 & 99 & 99 \\
\hline CO & 65 & 97 & 27 & 89.9 & 94 & 94 \\
\hline DIS & 27 & 40.3 & 12 & 36.4 & 39 & 39 \\
\hline
\end{tabular}

The above table describes the distribution of symptoms according to sex. All the symptoms were more common in males compared to females.

Table- $\mathbf{5}$ site with sexwise distribution :

\begin{tabular}{|c|c|c|c|c|c|c|}
\hline \multirow{2}{*}{ Site } & \multicolumn{2}{|c|}{ Male } & \multicolumn{2}{c|}{ Female } & \multicolumn{2}{c|}{ Total } \\
\cline { 2 - 7 } & No & $\%$ & No & $\%$ & No & $\%$ \\
\hline Anterior & 3 & 4.5 & 8 & 24.3 & 11 & 11 \\
\hline Posterior & 60 & 89.5 & 23 & 69.7 & 83 & 83 \\
\hline $\begin{array}{c}\text { Anterior } \\
\text { and } \\
\text { Posterior }\end{array}$ & 4 & 6 & 2 & 6 & 6 & 6 \\
\hline & 67 & 100 & 33 & 100 & 100 & 100 \\
\hline
\end{tabular}

The occurrence of posterior anal fissures is noted in $89.5 \%$ in males and about $69.7 \%$ in females are explained in the above table. The overall occurrence of posterior anal fissures is found to be $83 \%$. The occurrence of anterior anal fissures is noted in $4.5 \%$ in males and $24.3 \%$ in females. The presence of both anterior and posterior anal fissures is seen in $6 \%$ of both males and females. It is observed from the above table that the occurrence of chronic fissure in male is 41.52 with standard deviation 11.53 and in female 36.93 with standard deviation 11.28 . Out of 100 patients, who participated in my study, at the end of the 6 week follow up, $100 \%$ healing was present in the lateral internal sphincterotomy group. About $78 \%$ healing was present in the chemical sphincterotomy group.

Table 6 Rate Of Healing

\begin{tabular}{|c|c|c|c|c|}
\hline \multicolumn{2}{|c|}{} & \multicolumn{2}{|c|}{ Healing } & \multirow{2}{*}{ Total } \\
\hline \multirow{3}{*}{ Procedure } & & - & + & \\
\cline { 2 - 5 } & CS & 11 & 39 & 50 \\
\cline { 2 - 5 } & LS & 0 & 50 & 50 \\
\cline { 2 - 5 } & & 11 & 89 & 100 \\
\hline
\end{tabular}

Chi-square $=12.360, \mathrm{p}=0.000$

The above table shows the rate of healing. Out of 100 patients, 39 patients showed healing rate from chemical sphincterotomy and 89 patients showed healing rate from lateral internal sphincterectomy.

Table 7 Rate Of Recurrence

\begin{tabular}{|c|c|c|c|c|}
\hline & & \multicolumn{2}{|c|}{ Recurrence } & \multirow[t]{2}{*}{ Total } \\
\hline \multirow{4}{*}{ Procedure } & & - & + & \\
\hline & $\mathrm{CS}$ & 39 & 11 & 50 \\
\hline & LS & 50 & 0 & 50 \\
\hline & & 89 & 11 & 100 \\
\hline
\end{tabular}

Chi-square $=12.350, \mathrm{p}=0.000$

Out of 100 patients who had participated in my study, there was no recurrence in the lateral internal sphincterotomy group. 11 patients in the chemical sphincterotomy group experienced recurrence.

\section{Discussion}

Chronic anal fissure is the most common distressing problem that affect patient's day to day activity and hence deserves proper identification and adequate treatment to alleviate the pain ${ }^{5}$. There by improving the patient's quality of life. The main goal in treatment aspect lies in reducing the sphincter tone of the anal canal and reliving the sphincter spasm. There are two main modalities of treatment which are surgical sphincterotomy 
and chemical sphincterotomy, conservative management using analgesics and laxatives are being tried though. Among surgical sphincterotomy procedures performed, lateral internal sphincterotomy is the gold standard in treating chronic fissure ${ }^{6}$. chemical sphincterotomy is by using diltiazem gel, acalcium channel blocker which has shown promising results ${ }^{7}$. In the present study, a prospective comparative study of topical application of $2 \%$ diltiazem gel and lateral internal sphincterotomy has been done with regards to efficacy, adverse effect and complication in chronic fissure in ano. This study includes a total of 100 patients who present to the surgical out patient department at GMKMCH, Salem from Dec 2012 to June 2014. Patients are randomly grouped in to two, each group contains 50 patients, groups A patients are given Diltiazem ointment and in group B patients are subjected to lateral internal sphincterotomy and patients are followed up at 2,4,6,8 and 12 weeks and results are tabulated. In the present study the most commonly affected age group is 41-50 consisting of $33 \%$ and second most common age group affected is $31-40$ years consisting of $26 \%$. Occurrence is less between age group 11-20 and after 60 years. There is male preponderance consisting of $67 \%$ compared to female comprising $33 \%$ in my study. The presenting complaints in my study are painful defecation which is present in all patients, bleeding per rectum and constipation are also present in almost all patients and 39\% of patients presented with complaints of discharge. In my study, the occurrence of posterior anal fissure was noted to be $89.5 \%$ in males (60 out of 67 male ) and in females it is $69.7 \%$ (23 out of 33 females ). The overall incidence of post anal fissure was found to be $83 \%$ with the inference that post anal fissure is the commonest site. Anterior anal fissure was seen in $4.5 \%$ in male and $11 \%$ in female with the inference that anterior fissure is most common in females. Out of 100 patients in the study sentinel pile was present in $80 \%$ of the patients

Rate: Out of 50 patients in group A who used diltiazem gel , 39 patients (78\%) fissure healed completely between 4-8 weeks. In group B , 50 patients who underwent lateral internal sphincterotomy , 50 patients (100\%) healing was present by end of 4 weeks. In diltiazem group , 10 patients (20\%) were pain free at the end of 4 weeks, 21 patients (42\%) was pain free at the end of 8 weeks , 8 patients (16\%) were pain free by 12 weeks . 11 patients $(22 \%)$ were not of pain even at the end of 12 weeks. Fissure was completely healed in $39(78 \%)$ out of 50 patients by 12 weeks. In LIS group all the 50 patients were relieved of pain by end of 4 weeks. fissure was completely healed in all the 50 patients.

Complication Rate: In the study, out of 50 patients in the diltiazem group , 3 patients (6\%) experienced head ache and local irritation was present in 2 patients (4\%). Out of 50 patients in LIS group,15 patients experienced post operative pain which was which was relieved by end of $2^{\text {nd }}$ week.

Recurrence: Recurrence was seen in $11(22 \%)$, patients in diltiazem group and none in the LIS group. Comparison between Diltiazem gel therapy and internal sphincterotomy showed a difference in pain relief (p) and fissure healing $(\mathrm{p})$ which was stastistically significant ${ }^{8}$.

\section{Conclusion}

The current study shows results in favor of lateral internal sphincterotomy with healing rate of $100 \%$ with faster pain relief and minimal or no complication. Topical $2 \%$ diltiazem gel is an effective agent in the treatment of chronic fissure in ano. Although there is latency in the clearance of symptoms and lesion when compared to surgical sphincterotomy, this has shown minimal and insignificant adverse affect profile. Topical diltiazem can be safely prescribed for patients who are unfit or unwilling for surgery. The healing rate of the fissure is much slower compared to surgery but the need for hospital stay is abolished and it also reduces the psychological as well as financial burden on the patients. With a healing rate close to $80 \%$, topical $2 \%$ diltiazem therapy can be easily advised as the first line of treatment for chronic anal fissure. By comparing the above modalities of treatment for chronic fissure we conclude that Lateral Internal Sphincterotomy appears to be the better line of treatment as there is $100 \%$ healing rate.

\section{References}

[1]. “Anal Fissure - Basics - Epidemiology” Best Practice. British Medical Journal. Apr 23, 2012. Retrieved 30 June 2012.

[2]. Renzi, A.; Brusciano, L.; Pescatori, M.; Izzo, D.; Napolitano, V.; Rossetti, G.; del Genio, G.; del Genio, A. (January 2005).

[3]. "Pneumatic Balloon Dilatation for Chronic Anal Fissure: A Prospective, Clinical, Endosonographic, and Manometric Study". Diseases of the Colon and Rectum 48 (1): 121-126.

[4]. Maria G, Brisinda G. Botulinum injections in the internal anal sphincter for treatment of chronic anal fissures. Long-term results after two different dose regimens. Ann Surg.

[5]. Jost WH. One hundred cases of anal fissure treated with botulin toxin: early and long-term results. Dis colon rectum. 1997 Sep;40(9):1929-1932.

[6]. Hanumanthappa MB, rithin suvarna et al, topical diltiazem superior to the topical lignocaine in the treatment of chronic anal fissure. Journal of clinical and diagnostic research. 2012 aug 6(6): 1014-17.

[7]. Basic human anatomy O'Rahilly, Müller, Carpenter \& Swenson .

[8]. Z Haq M Rahman et al chemical sphincterotomy - First line of treatment for chronic anal fissure - mymensingh Med J (2005) $14 ; 88-90$.

[9]. Habib Ullah Khan, Irfan Shokr, et al -effect of topical Glyceryl trinitrate on the management of acute anal fissure- RMJ volume 31, Number 2, Jul - Dc 2006. 
[10]. Dr. Ayesha Shaukat, Dr Farid Zafar -et al chronic Anal fissure ; Role of chemical Sphincterotomy ; Professional Med J Sept 2006 ;13 (3) ; 354-357.

[11]. Dr. Tariq Wahab Khanzada, Dr Abdul Samad- Chronic Anal fessures ; topical Glyceryl trinitrate versus lateral internal sphincterotomy - professional Med J Jun $2007 ; 14$ (2) ; 318 - 322.

[12]. P. Gupta, Internal anal sphincterolysis for chronic anal fissure ; the American Journal of Surgery, Volume 194, Issue 1, page 13-16.

[13]. Madalinski M, Kalinowski L. Novel options for the pharmacological treatment of chronic anal fissure - role of botulin toxin. Current Clinical Pharmacology 2009;4(1):47-52.

[14]. Dhawan S, Chopra S. Non-surgical approaches for the treatment of anal fissures. Am J Gastroenterology 2007;102:1312-21.

[15]. Carapeti EA, Kamm MA, McDonald PI, et al. Randomised controlled trial shows that glyceryl trinitrate heals anal fissures, higher doses are not more effective, and there is a high recurrence rate. Gut 1999;44:727-30.

[16]. Bhardwaj R, Vaizey CJ, Bulos PB, et al. Neuromyogenic properties of internal sphincter: therapeutic rationale for anal fissures.Gut 2000;46:861-8.

[17]. Chrysos E, Xynos E, Tzovaras G, et al. Effect of nifedipine on rectoanal motility. Dis Colon Rectum 1996;39:212-6.

[18]. Jonas M, Speake W, Scholefield JH, Diltiazem heals glyceryl trinitrate resistant chronic anal fissures: A prospective study. Dis Colon Rectum 2002;45(8):1091-5.

[19]. Carapeti EA, Kamm MA, Phillips RK. Topical diltiazem and bethanechol decrease anal sphincter pressure and heal anal fissures without side effects. Dis Colon Rectum 2000;43:1359-1362. 